\title{
Pelabelan Total Super Sisi Ajaib Pada Graf Caterpillar Teratur $C_{4_{n}}$
}

\author{
Triyani, Siti Rahmah Nurshiami, Mutia Nur Estri \\ Program Studi Matematika, Jurusan MIPA \\ Fakultas Sains dan Teknik \\ Universitas Jenderal Soedirman \\ Jl. Dr. Soeparno Karangwangkal Purwokerto \\ trianisr@yahoo.com.au, nurshiami@yahoo.co.id, mutia_ne_yusuf@yahoo.com
}

\begin{abstract}
ABSTRAK
Graf Super Sisi Ajaib merupakan graf yang dapat dilabeli dengan pelabelan Total Super Sisi Ajaib (TSSA). Pelabelan TSSA dari suatu graf $G(V, E)$ dengan himpunan titik $V$ dan himpunan sisi $E$ adalah suatu fungsi bijektif yang memetakan himpunan titik dan sisi ke himpunan bilangan bulat positif $1,2, \ldots, \quad V \cup E$ sedemikian sehingga jumlah label sisi dan label ke dua titik yang insiden dengan sisi tersebut sama untuk semua sisi di graf $G$, disebut konstanta ajaib. Hasil penelitian ini menunjukkan bahwa graf Caterpillar Teratur $C_{4_{n}}$ merupakan graf Super Sisi Ajaib dengan konstanta ajaib $k$ $=\frac{25 n+2}{2}$, untuk $n$ bilangan genap dan $k=\frac{25 n+5}{2}$, untuk $n$ bilangan ganjil.
\end{abstract}

Kata kunci: Graf super sisi ajaib, pelabelan total super sisi ajaib, konstanta ajaib

\section{ABSTRACT}

A super edge magic graph is a graph that can be labeled with edge eagic total (EMT) labeling. EMT labeling of a graph $G(V, E)$ with vertex set $V$, and edge set $E$ is a bijective function that maps the set of vertices and edges to the set of positive integers 1,2,..., $V \cup E$ such that the number of label for edges and two vertices that incident with its edge are equal for all edges in a graph $G$. It is called the magic constant. The results of this study show that the Caterpillar Regular graph $\boldsymbol{C}_{\boldsymbol{4}_{n}}$ is an edge magic super graf with magic constant $k=\frac{25 n+2}{2}$, for $n$ even and $k=\frac{25 n+5}{2} \quad k=\frac{25 n+5}{2}, n$ odd.

Keywords: super edge magic graph, edge eagic total labeling, magic constant

\section{Pendahuluan}

Secara umum pelabelan graf adalah suatu pemetaan dari himpunan titik, himpunan sisi, atau himpunan titik dan sisi dari suatu graf ke bilangan bulat positif. Pelabelan Total Sisi Ajaib (TSA) dari suatu graf $G(V, E)$ dengan himpunan titik $V$ dan himpunan sisi $E$ adalah suatu fungsi bijektif yang memetakan himpunan titik dan sisi ke himpunan bilangan bulat positif sedemikian sehingga jumlah bobot setiap sisi dengan bobot titik yang insiden dengan sisi tersebut sama. Pelabelan ini dikatakan total karena semua sisi dan titik di graf $G$ diberi label dan dikatakan sisi ajaib karena untuk setiap sisi di graf $G$, jumlah label sisi dan label kedua titik yang insiden dengan sisi tersebut adalah konstanta $k$. Nilai $k$ ini selanjutnya disebut konstanta ajaib untuk graf $G$. Jika label yang dikenakan pada titik di graf $\mathrm{G}$ adalah bilangan terurut dari 
$1,2, \ldots,|V|$, maka pelabelannya disebut pelabelan Total Super Sisi Ajaib (TSSA). Graf yang dapat dilabeli secara TSSA disebut graf Super Sisi Ajaib.

Tidak semua graf merupakan graf Super Sisi Ajaib. Enomoto et al, [1] menduga bahwa graf pohon adalah graf Super Sisi Ajaib. Dugaan tersebut diverifikasi oleh beberapa peneliti hingga saat ini untuk beberapa kelas graf pohon, diantaranya graf pohon pisang/banana tree graph oleh Swaminathan dan Jeyanthi [5], graf Caterpillar oleh Imron [2], graf Caterpillar-like trees oleh Sugeng [4], serta gabungan graf bintang dan lintasan oleh Sudarsana [3]. Pada penelitian ini memverifikasi pelabelan TSSA pada graf Caterpillar Teratur $C_{4_{n}}$ mengingat Caterpillar juga merupakan graf pohon.

\section{Metode Penelitian}

Metode dalam penelitian ini adalah ekperimental dengan tahapan sebagai berikut. Tahap I adalah kajian literature, penelusuran pustaka tentang Pelabelan Graf, konstruksi pelabelan TSSA pada beberapa kelas graf. Tahap II adalah identifikasi dan perumusan masalah. Kegiatan yang dilakukan pada tahap ini adalah menggali masalah riil dan mencoba menyelesaiakannya dengan topik yang di gunakan dalam penelitian ini yaitu pelabelan TSSA. Tahap III membuat formula pelabelan TSSA, kegiatan yang dilakukan pada tahap ini adalah membuat formulasi label titik dan label sisi dengan pelabelan TSSA pada graf Caterpillar. Tahap IV adalah Tahap Verifikasi, pada tahapan ini hasil yang telah diperoleh pada tahap ke-3 dituangkan dalam bentuk teorema.

\section{Hasil dan Pembahasan}

Hasil dari penelitian ini berupa teori yang dituangkan dalam bentuk teorema yang menyatakan bahwa graf Caterpillar Teratur $C_{4_{n}}$ merupakan graf Super Sisi Ajaib, yaitu graf yang dapat dilabeli dengan pelabelan TSSA. Graf Caterpillar Teratur $C_{4_{n}}$ mempunyai titik sebanyak $5 n$ yaitu titik $w_{1}, w_{2}, \ldots, w_{2 n}, x_{1}, x_{2}, \ldots, x_{2 n}, z_{1}, z_{2}, \ldots, z_{n}$ dan sisi sebanyak $5 n$ - 1 . Himpunan titik dan himpunan sisi dari graf Caterpillar Teratur $C_{4_{n}}$ didefinisikan sebagai berikut :

$$
\begin{gathered}
V\left(C_{4_{n}}\right)=\left\{w_{i} \mid 1 \leq i \leq 2 n\right\} \cup\left\{x_{i} \mid 1 \leq i \leq 2 n\right\} \cup\left\{z_{i} \mid 1 \leq i \leq n\right\} \\
E\left(C_{4_{n}}\right)=\left\{w_{i} z_{j} \mid 1 \leq i \leq 2 n, 1 \leq j \leq n\right\} \cup\left\{x_{i} z_{j} \mid 1 \leq i \leq 2 n, 1 \leq j \leq n\right\} \\
\cup\left\{z_{i} z_{i+1} \mid 1 \leq i \leq n-1\right\}
\end{gathered}
$$




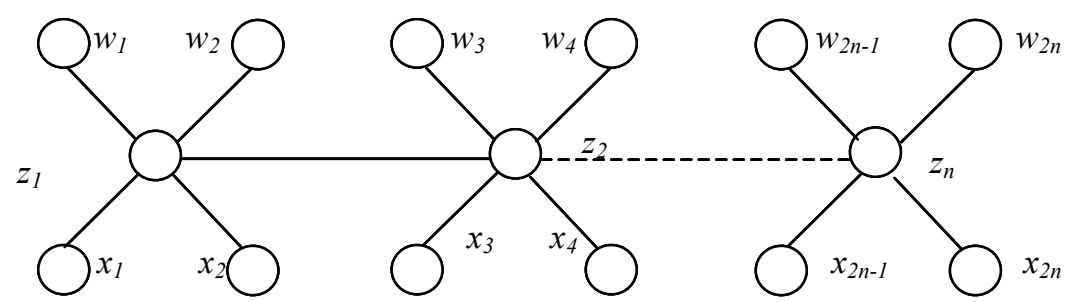

Gambar 1. Graf Caterpillar teratur $C_{4_{n}}$

Teorema 1. Graf Caterpillar Teratur $C_{4_{n}}$ dengan $n$ bilangan genap adalah Graf Super Sisi Ajaib dengan konstanta ajaib $k=\frac{25 n+2}{2}$.

\section{Bukti:}

Ambil $w_{i}, x_{i}, z_{k}, w_{i} z_{j}, x_{i} z_{k}, z_{k} z_{k-1} \in V \cup E$ dengan $1 \leq i \leq 2 n, 1 \leq j \leq 2 n, 1 \leq k \leq n$. Definisikan sebuah pelabelan $f: V \cup E \rightarrow\{1,2, \ldots, 10 n-1\}$ sebagai berikut:

$$
\begin{aligned}
& f\left(w_{i}\right)= \begin{cases}\frac{5\left(\frac{i+1}{2}\right)-3}{2}, & i=1,5,9, \ldots, 2 n-3 \\
\frac{5\left(\frac{i+2}{2}\right)-6}{2} & , i=2,6,10, \ldots, 2 n-2 \\
\frac{5 n+5\left(\frac{i-1}{2}\right)-1}{2}, & i=3,7,11, \ldots, 2 n-1 \\
\frac{5 n+5\left(\frac{i}{2}\right)-4}{2} & , \quad i=4,8,12, \ldots, 2 n\end{cases} \\
& f\left(z_{\left(\frac{i}{2}\right)}\right)=\left\{\begin{array}{cc}
\frac{5 n+5\left(\frac{i+2}{2}\right)-8}{2}, & i=2,6,10, \ldots, 2 n-2 \\
\frac{5\left(\frac{i}{2}\right)}{2} & , \quad i=4,8,12, \ldots, 2 n
\end{array}\right. \\
& f\left(z_{\left(\frac{i+1}{2}\right)}\right)=\left\{\begin{array}{cc}
\frac{5 n+5\left(\frac{i+2}{2}\right)-3}{2}, & i=1,5,9, \ldots, 2 n-3 \\
\frac{5\left(\frac{i-1}{2}\right)+5}{2} & , \quad i=3,7,11, \ldots, 2 n-1
\end{array}\right.
\end{aligned}
$$




$$
\begin{aligned}
& f\left(w_{i} z_{\left(\frac{i+1}{2}\right)}\right)= \begin{cases}\frac{20 n-10\left(\frac{i+1}{2}\right)+8}{2}, & i=1,5,9, \ldots, 2 n-3 \\
\frac{20 n-10\left(\frac{i-1}{2}\right)-2}{2} & , \quad i=3,7,11, \ldots, 2 n-1\end{cases} \\
& f\left(w_{i} z_{\left(\frac{i}{2}\right)}\right)= \begin{cases}\frac{20 n-10\left(\frac{i+2}{2}\right)+16}{2}, & i=2,6,10, \ldots, 2 n-2 \\
\frac{20 n-10\left(\frac{i}{2}\right)+6}{2} & , \quad i=4,8,12, \ldots, 2 n\end{cases}
\end{aligned}
$$

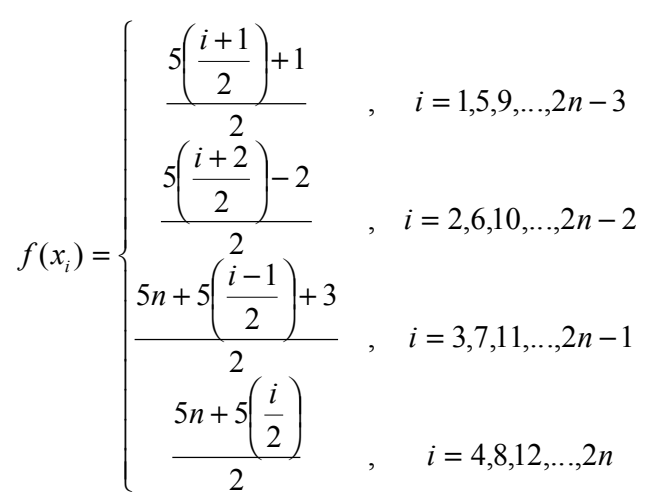

$$
\begin{aligned}
& f\left(x_{i} z_{\left(\frac{i+1}{2}\right)}\right)= \begin{cases}\frac{20 n-10\left(\frac{i+1}{2}\right)+4}{2}, & i=1,5,9, \ldots, 2 n-3 \\
\frac{20 n-10\left(\frac{i-1}{2}\right)-6}{2}, & i=3,7,11, \ldots, 2 n-1\end{cases} \\
& f\left(x_{i} z_{\left(\frac{i}{2}\right)}\right)= \begin{cases}\frac{20 n-10\left(\frac{i+2}{2}\right)+12}{2}, & i=2,6,10, \ldots, 2 n-2 \\
\frac{20 n-10\left(\frac{i}{2}\right)+2}{2} & , \quad i=4,8,12, \ldots, 2 n\end{cases} \\
& f\left(z_{i} z_{i+1}\right)=10 n-5 i \quad, \quad i=1,2,3,4, \ldots, n-1
\end{aligned}
$$

Fungsi $f$ di atas merupakan fungsi bijektif. Selanjutnya dapat ditunjukkan jumlah label sisi dan label kedua titik yang insiden dengan sisi tersebut dalam hal ini disebut konstanta ajaib $k$ untuk graf Caterpillar Teratur $C_{4_{n}}, n$ bilangan 
genap. Perhatikan graf Caterpillar Teratur $C_{4_{n}}$ pada Gambar 1. Tanpa mengurangi keumuman, sisi $w_{i} z_{i}$ berinsiden dengan titik $w_{i}$ dan $z_{i}$, sehingga konstanta ajaib $k$ untuk sisi $w_{i} z_{i}$ dengan titik $w_{i}$ dan $z_{i}$ ditentukan dengan menghitung jumlah label sisi $f\left(w_{i} z_{i}\right)$ dengan label titik $f\left(w_{i}\right)$ dan $f\left(z_{i}\right)$ seperti persamaan (10).

$$
\begin{aligned}
k & =f\left(w_{i}\right)+f\left(w_{i} z_{\left(\frac{i+1}{2}\right)}\right)+f\left(z_{\left(\frac{i+1}{2}\right)}\right) \quad i=1,5,9, \ldots, 2 n-3 \\
& =\frac{5\left(\frac{i+1}{2}\right)-3}{2}+\frac{20 n-10\left(\frac{i+1}{2}\right)+8 \quad 5 n+5\left(\frac{i+1}{2}\right)-3}{2}+\frac{25 n+2}{2}
\end{aligned}
$$

Dengan cara yang sama, dapat ditentukan konstanta ajaib untuk sisi dan titik

yang lain, seperti persamaan (11) - (14).

$$
\begin{aligned}
k= & f\left(x_{i}\right)+f\left(x_{i} z_{\left(\frac{i+1}{2}\right)}\right)+f\left(z_{\left(\frac{i+1}{2}\right)} \quad i=2,6,10, \ldots, 2 n-2\right. \\
= & \frac{5\left(\frac{i+2}{2}\right)-2}{2}+\frac{20 n-10\left(\frac{i+2}{2}\right)+12}{2}+\frac{5 n+5\left(\frac{i+2}{2}\right)-8}{2}=\frac{25 n+2}{2} \\
k= & f\left(w_{i}\right)+f\left(w_{i} z_{\left(\frac{i+1}{2}\right)}\right)+f\left(z_{\left(\frac{i+1}{2}\right)}\right) \quad i=3,7,11, \ldots, 2 n-1 \\
= & \frac{5 n+5\left(\frac{i-1}{2}\right)-1}{2}+\frac{20 n-10\left(\frac{i-1}{2}\right)-2}{2}+\frac{5\left(\frac{i-1}{2}\right)+5}{2}=\frac{25 n+2}{2} \\
k= & f\left(x_{i}\right)+f\left(x_{i} z_{\left(\frac{i}{2}\right)}\right)+f\left(z_{\left(\frac{i}{2}\right)}\right) \quad i=4,8,12, \ldots, 2 n \\
& =\frac{5 n+5\left(\frac{i}{2}\right)}{2}+\frac{20 n-10\left(\frac{i}{2}\right)+2}{2}+\frac{5\left(\frac{i}{2}\right)}{2}=\frac{25 n+2}{2} \\
k= & f\left(z_{i}\right)+f\left(z_{i} z_{i+1}\right)+f\left(z_{i+1}\right) \\
= & \frac{5 n+5 i-3}{2}+\frac{20 n-10 i}{2}+\frac{5 i+5}{2}=\frac{25 n+2}{2}
\end{aligned}
$$

Dengan demikian graf Caterpillar Teratur $C_{4_{n}}$ dengan $n$ bilangan genap adalah Graf Super Sisi Ajaib dengan konstanta ajaib $k=\frac{25 n+2}{2}$. 
Teorema 2. Graf Caterpillar Teratur $C_{4_{n}}$ dengan $n$ bilangan ganjil adalah Graf Super Sisi Ajaib dengan konstanta ajaib $k=\frac{25 n+5}{2}$.

\section{Bukti:}

Ambil $w_{i}, x_{i}, z_{k}, w_{i} z_{j}, x_{i} z_{k}, z_{k} z_{k-1} \in V \cup E$ dengan $1 \leq i \leq 2 n, 1 \leq j \leq 2 n, 1 \leq k \leq n$. Definisikan sebuah pelabelan $f: V \cup E \rightarrow\{1,2, \ldots, 10 n-1\}$ sebagai berikut:

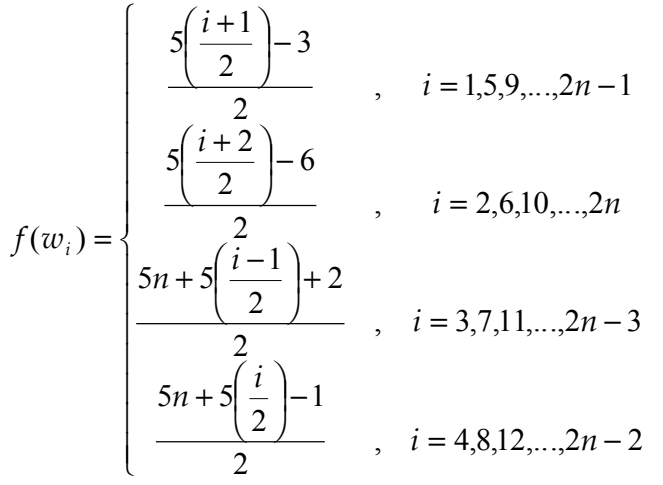

$$
\begin{aligned}
& f\left(x_{i}\right)=\left\{\begin{array}{cc}
\frac{5\left(\frac{i+1}{2}\right)+1}{2} & , \quad i=1,5,9, \ldots, 2 n-1 \\
\frac{5\left(\frac{i+2}{2}\right)-2}{2} & , \quad i=2,6,10, \ldots, 2 n \\
\frac{5 n+5\left(\frac{i-1}{2}\right)+6}{2}, & i=3,7,11, \ldots, 2 n-3 \\
\frac{5 n+5\left(\frac{i}{2}\right)+3}{2} & , \quad i=4,8,12, \ldots, 2 n-2
\end{array}\right. \\
& f\left(z_{\left(\frac{i}{2}\right)}\right)=\left\{\begin{array}{cc}
\frac{5 n+5\left(\frac{i+2}{2}\right)-5}{2}, & i=2,6,10, \ldots, 2 n \\
\frac{5\left(\frac{i}{2}\right)}{2} & , \quad i=4,8,12, \ldots, 2 n-2
\end{array}\right. \\
& f\left(z_{\left(\frac{i+1}{2}\right)}\right)= \begin{cases}\frac{5 n+5\left(\frac{i+1}{2}\right)}{2}, & i=1,5,9, \ldots, 2 n-1 \\
\frac{5\left(\frac{i-1}{2}\right)+5}{2} & , \quad i=3,7,11, \ldots, 2 n-3\end{cases}
\end{aligned}
$$




$$
\begin{aligned}
& f\left(w_{i} z_{\left(\frac{i+1}{2}\right)}\right)= \begin{cases}\frac{20 n-10\left(\frac{i+1}{2}\right)+8}{2}, & i=1,5,9, \ldots, 2 n-1 \\
\frac{20 n-10\left(\frac{i-1}{2}\right)-2}{2}, & i=3,7,11, \ldots, 2 n-3\end{cases} \\
& f\left(w_{i} z_{\left(\frac{i}{2}\right)}\right)= \begin{cases}\frac{20 n-10\left(\frac{i+2}{2}\right)+16}{2}, & i=2,6,10,, \ldots, 2 n \\
\frac{20 n-10\left(\frac{i}{2}\right)-6}{2} & , \quad i=4,8,12, \ldots, 2 n-2\end{cases} \\
& f\left(x_{i} z_{\left(\frac{i+1}{2}\right)}\right)= \begin{cases}\frac{20 n-10\left(\frac{i+1}{2}\right)+4}{2}, & i=1,5,9, \ldots, 2 n-1 \\
\frac{20 n-10\left(\frac{i-1}{2}\right)-6}{2}, & i=3,7,11, \ldots, 2 n-3\end{cases} \\
& f\left(x_{i} z_{\left(\frac{i}{2}\right)}\right)= \begin{cases}\frac{20 n-10\left(\frac{i+2}{2}\right)+12}{2}, & i=2,6,10, \ldots, 2 n \\
\frac{20 n-10\left(\frac{i}{2}\right)+2}{2} & , \quad i=4,8,12, \ldots, 2 n-2\end{cases} \\
& f\left(z_{i} z_{i+1}\right)=10 n-5 i \quad, \quad i=1,2,3,4, \ldots, n-1
\end{aligned}
$$

Fungsi $f$ di atas merupakan fungsi bijektif. Selanjutnya dapat ditunjukkan konstanta ajaib untuk graf Caterpillar Teratur $C_{4_{n}}$ untuk $n$ bilangan ganjil, dengan menunjukkan jumlah label sisi dan label dua titik yang insiden dengan sisi tersebut sama.

$$
\begin{aligned}
k & =f\left(w_{i}\right)+f\left(w_{i} z_{\left(\frac{i+1}{2}\right)}\right)+f\left(z_{\left(\frac{i+1}{2}\right)}\right) \quad i=1,5,9, \ldots, 2 n-1 \\
& =\frac{5\left(\frac{i+1}{2}\right)-3}{2}+\frac{20 n-10\left(\frac{i+1}{2}\right)+8}{2}+\frac{5 n+5\left(\frac{i+1}{2}\right)}{2}=\frac{25 n+5}{2} \\
k & =f\left(x_{i}\right)+f\left(x_{i} z_{\left(\frac{i+1}{2}\right)}\right)+f\left(z_{\left(\frac{i+1}{2}\right)}\right) \quad i=3,7,11, \ldots, 2 n+1 \\
& =\frac{5 n+5\left(\frac{i-1}{2}\right)+6}{2}+\frac{20 n-10\left(\frac{i-1}{2}\right)-6}{2}+\frac{5\left(\frac{i-1}{2}\right)+5}{2}=\frac{25 n+5}{2}
\end{aligned}
$$




$$
\begin{aligned}
k & =f\left(w_{i}\right)+f\left(w_{i} z_{\left(\frac{i+1}{2}\right)}\right)+f\left(z_{\left(\frac{i+1}{2}\right)}\right) \quad i=2,6,10, \ldots, 2 n \\
& =\frac{5 n+5\left(\frac{i-1}{2}\right)+2}{2}+\frac{20 n-10\left(\frac{i-1}{2}\right)-2}{2}+\frac{5\left(\frac{i-1}{2}\right)+5}{2}=\frac{25 n+5}{2} \\
k & =f\left(x_{i}\right)+f\left(x_{i} z_{\left(\frac{i}{2}\right)}\right)+f\left(z_{\left(\frac{i}{2}\right)}\right) \quad i=4,8,12, \ldots, 2 n+2 \\
& =\frac{5 n+5\left(\frac{i}{2}\right)+3}{2}+\frac{20 n-10\left(\frac{i}{2}\right)+2}{2}+\frac{5\left(\frac{i}{2}\right)}{2}=\frac{25 n+5}{2} \\
k & =f\left(z_{i}\right)+f\left(z_{i} z_{i+1}\right)+f\left(z_{i+1}\right) \\
& =\frac{5 n+5 i}{2}+\frac{20 n-10 i}{2}+\frac{5 i+5}{2}=\frac{25 n+5}{2} .
\end{aligned}
$$

Dengan demikian graf Caterpillar Teratur $C_{4_{n}}$ dengan $n$ bilangan ganjil adalah Graf Super Sisi Ajaib dengan konstanta ajaib $k=\frac{25 n+5}{2}$.

Berikut contoh pelabelan super sisi ajaib pada graf Caterpillar Teratur $C_{4_{6}}$ dengan konstanta ajaib $k=76$, dan pada graf Caterpillar Teratur $C_{4_{5}}$ dengan konstanta ajaib $k=65$.

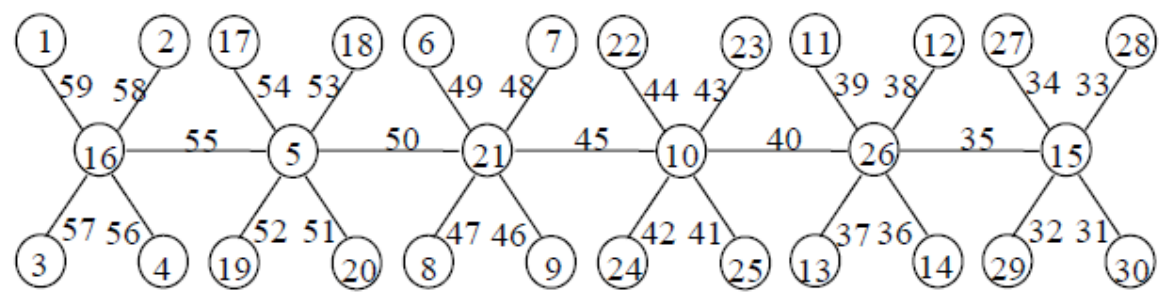

Gambar 2. Pelabelan super sisi ajaib pada graf Caterpillar teratur $C_{4_{6}}$

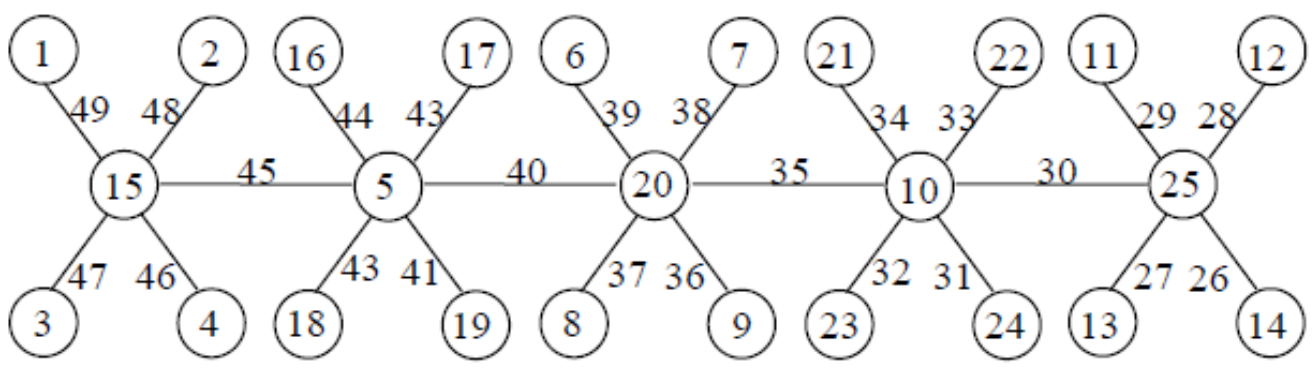

Gambar 3. TSSA pada graf Caterpillar teratur $C_{4_{5}}$ 


\section{Simpulan}

Kesimpulan yang dapat diperoleh dari penelitian ini yaitu graf Caterpillar Teratur $C_{4_{n}}$ merupakan Graf Super Sisi Ajaib. Konstanta ajaib dari pelabelan TSSA pada graf Caterpillar Teratur $C_{4_{n}}$ adalah $k=\frac{25 n+2}{2}$ untuk $n$ bilangan genap, dan $k=\frac{25 n+5}{2}$ untuk $n$ bilangan ganjil.

\section{Daftar Pustaka}

1. Enomoto, H., A.S.Llado, T. Nakamigawa, G. Ringel. 1998., Super Edge Magic Graph. SUT Journal of Mathematics 2. p105.

2. Imron, C, 2004., Several Ways to Obtain Edge-Magic Total Labeling of Caterpillars. International Workshop on Graph Labeling (IWOGL), Malang.

3. Sudarsana, I. W., Noviana, N., Musdalifah S., Kasim, A. A., 2013., Pelabelan Total Sisi Ajaib Super (TSAS) pada Gabungan Graf Bintang Ganda dan Lintasan. Journal of Natural Science FMIPA vol. 2 No. 1.

4. Sugeng A. K., Denny R. Silaban. 2007., On Edge Magic Total Labelling of Caterpillar-Like Trees. Proceedings SEAMS-GMU Conference.

5. Swaminathan V., Jeyanthi, P., 2006., Super Edge Magic Strength of Fire Crackers, Banana Trees and unicyclic graphs. Discrete Math. 